\title{
The Renal Reabsorption of Glucose in the Developing Canine Kidney: A Study of Glomerulotubular Balance
}

\author{
Billy S. Arant, Jr., Ghester M. Edelmann, Jr., and Martin A. Nash ${ }^{[56]}$ \\ Department of Pediatrics, Division of Pediatric Nephrology, Rose F. Kennedy Center, Albert Einstein \\ College of Medicine, Bronx, New York, USA
}

\section{Extract}

Twenty puppies, $18 \mathrm{hr}-40$ days of age, were used to investigate the relation between maximal tubular reabsorption of glucose $(\mathrm{TmG})$ and glomerular filtration rate (GFR) during maturation. The renal threshold for glucose was examined in an attempt to obtain information concerning functional heterogeneity. There was a slow increase in dry kidney weight (DKW) over the first 2 weeks of life, relative to the more rapid rate noted thereafter. Examination of the clearance of inulin $\left(\mathrm{C}_{\mathrm{IN}}\right)$ and TmG revealed a pattern of increase with age similar to that observed for the relation of DKW to age. The ratio of $\mathrm{TmG}$ to $\mathrm{C}_{\mathrm{rN}}$ initially was high (4.22), fell markedly over the first few days, and thereafter continued to decrease exponentially until levels were achieved that were similar to values found in adult animals (2.75-3.31). These data suggest that the documented anatomical glomerular preponderance in the infant kidney may not have a consistent functional correlate. Analysis of the glucose threshold as a function of age revealed a statistically significant positive regression; however, the increase with age was small (range 190-254 mg/100 ml), and all values fell within the $95 \%$ confidence limits for adult thresholds. A comparison of splay between the youngest and oldest puppies demonstrates an increase in splay and thus in functional heterogeneity of the younger animals, a finding which may reflect a population of nephrons with relative glomerular preponderance, despite the presence of glomerulotubular balance for the kidney as a whole.

\section{Speculation}

Current evidence, including that of the present investigation, suggests that although functional tubular capacity at birth may be limited, glomerulotubular balance is maintained.

\section{Introduction}

A sustained balance between GFR and tubular reabsorption is one of the most consistently observed phenomena in renal physiology. When Tudvad [44] re- ported in 1949 that the ratio of the TmG to the $\mathrm{C}_{\mathrm{IN}}$ was lower in infants than in children and adults, it appeared that such balance did not exist in the immature kidney, but rather that the quantity of glomerular filtrate exceeded the tubular reabsorptive capacity, 
accounting for inefficient conservation of filtered substances. In other studies in infants low ratios of the tubular maximum for $p$-aminohippurate $(\mathrm{PAH})$ and the clearance of PAH to the $\mathrm{C}_{\mathrm{IN}}[4,34,45,46,48]$, and low fractional reabsorption of phosphate $[7,12,26,31]$ were observed. Supported by morphologic studies of the immature kidney, which demonstrated relatively smaller tubules than glomeruli, these early data were synthesized into a formal concept of glomerulotubular imbalance with relative glomerular preponderance as a major characteristic of the immature kidney [14-16]. Recently, however, several studies have suggested that such a broad generalization may not be accurate and that balance similar to the mature state indeed may exist, at least for some of the substances handled by the immature kidney $[6,20,42,43]$.

Anatomical studies of the immature kidney have demonstrated greater heterogeneity in glomerulotubular relations than in the adult kidney [17, 29]. If this heterogeneity of structure has a functional counterpart, the existence of nephrons with large glomeruli and small tubules would be expected to result in a low threshold for glucose, a feature of the immature kidney that has not been investigated previously.

Inasmuch as it was the early work with glucose which provided the main support for the theory of glomerulotubular imbalance [44], the present studies were designed to reinvestigate the relation between TmG and GFR during maturation of the canine kidney. During the course of these studies, the renal threshold for glucose was examined in an attempt to obtain information concerning functional heterogeneity.

\section{Materials and Methods}

Twenty healthy mongrel puppies, $18 \mathrm{hr}-40$ days of age, obtained from unweaned litters whelped in our animal quarters, were used to investigate the glucose titration curve in the developing canine kidney.

Each puppy was separated from the litter 2 hours before the study. Atropine sulfate $(0.5 \mathrm{mg} / \mathrm{kg}$ body wt) was injected subcutaneously $45 \mathrm{~min}$ before intravenous or intraperitoneal induction and intravenous maintenance of light anesthesia with Inactin [50]. The animal was placed in a supine position on a heated animal board. A tracheostomy tube was inserted and connected to a respirator [51]. Solutions were infused and blood sampled from cannulae in the right external jugular vein and the left femoral artery, respectively.
Urine was obtained through soft polyethylene tubing, inserted into each ureter through a small midline suprapubic incision and extended to the level of the renal pelvis. Urine samples were collected directly into glass tubes, which were weighed to determine volume. Careful attention was given to fluid balance so as to insure an adequate urine flow while minimizing extracellular volume expansion.

After a priming dose of $10 \%$ inulin $(0.5 \mathrm{ml} / \mathrm{kg}$ body $w t$ ), an infusion of inulin in $0.85 \% \mathrm{NaCl}$ was administered at the rate of $0.08 \mathrm{ml} / \mathrm{min}$ throughout the remainder of the experiment. A separate infusion of $0.45 \% \mathrm{NaCl}$ was administered at a rate of $0.3 \mathrm{ml} / \mathrm{min} /$ $\mathrm{kg}$ body wt during a $30-\mathrm{min}$ period of equilibration, after which this solution was replaced by successive infusions of 10 and $20 \%$ dextrose in water at $0.1 \mathrm{ml} /$ min and $50 \%$ dextrose in water at 0.1 and $0.3 \mathrm{ml} / \mathrm{min}$. An equilibration period of $15 \mathrm{~min}$ was allowed after changing either the concentration or rate of infusion, followed by two 10-min collection periods. Body weights determined at the beginning and end of each experiment on a balance accurate to $0.1 \mathrm{~g}$ changed no more than $\pm 5 \%$. All animals were in positive fluid balance at the time TmG was reached. The animals were killed by an anesthetic overdose at the end of the procedure, at which time the kidneys were removed for determination of wet and dry weights.

Throughout the experiments, serial measurements were made of hemoglobin, hematocrit, body temperature, arterial blood pressure, arterial $\mathrm{pH}$, and $\mathrm{pCO}_{2}$ (which was maintained at $35-40 \mathrm{~mm} \mathrm{Hg}$ by appropriate adjustment of the respirator). The cells from each $0.5-1.0-\mathrm{ml}$ blood sample were returned to the animal in order to maintain the hematocrit at or near control levels.

Urine and plasma samples were analyzed in duplicate. Glucose was determined using a glucose oxidase method [5, 36, 52]. The diphenylamine method as modified by Walser et al. [47] was used for determination of inulin. Blood $\mathrm{pH}$ and $\mathrm{pCO}_{2}$ were determined using an AME I Radiometer [53].

The renal threshold for glucose was taken as the plasma level at which glucose was first detected in the urine in increasing amounts. The first appearance of glucose could not be used to denote the threshold, inasmuch as concentrations in urine at the beginning of the experiments ranged as high as $40 \mathrm{mg} / 100 \mathrm{ml}$. The TmG was determined by averaging the values for glucose reabsorption from three or more periods during which the rate of reabsorption was stable despite 
increasing filtered loads which exceeded reabsorption by a factor of $>1.4$, with three exceptions. One puppy at 14 days of age and the 18-day-old puppy had ratios of filtered load to amount reabsorbed of 1.1 and 1.2, respectively. In subsequent experimental periods, the ratios increased to 1.4 and 1.7 , while reabsorption remained constant. Because fractional sodium excretion increased to $4 \%$ and $3 \%$, these periods were not included in the calculation of TmG. For several experimental periods before the termination of the study in the 40-day-old animal, reabsorption remained constant despite increasing filtered loads. In this puppy the highest ratio achieved was 1.2. The values from periods at the end of the studies in which sodium excretion was increasing were discarded if the rate of glucose reabsorption was constant or decreasing. TmG may not have been achieved in the youngest animals as, in some of these puppies, glucose reabsorption continued to rise with increased filtered loads even though fractional sodium excretion increased to levels as high as $25 \%$. In these animals TmG was calculated by averaging the two or three highest reabsorptive rates at glucose values in plasma of less than $1,200 \mathrm{mg} / 100 \mathrm{ml}$, as, at higher values of glucose in plasma, there was a consistent fall in glomerular filtration rate. The $\mathrm{C}_{\mathrm{rN}}$ was accepted as the glomerular filtration rate, the control values having been determined before the infusion of any glucose-containing solution. The ratio of $\mathrm{TmG}$ to $\mathrm{C}_{\mathrm{IN}}$ was calculated by dividing the average $T m G$ by the average $\mathrm{C}_{\mathrm{IN}}$ of corresponding periods. Conventional methods of statistical analysis were employed [41]. The computer program (POLFIT) used for the calculation of nonlinear regression is part of the library of the Albert Einstein College of Medicine.

\section{Results}

Pertinent data on all animals are shown in Table I. The relation of kidney weight to age is demonstrated in Fig. 1. There was a slow increase in DKW over the first 2 weeks of life, relative to the more rapid rate noted thereafter. This increase in weight presumably reflected the predominant growth of the proximal tubule $[17,30]$. Kidney water increased linearly over the time period studied. The relation between dry and wet kidney weights (DKW/WKW) reflected the marked increase in water content during the first few days, as DKW changed relatively little. After 3 weeks of age, the rapid increase in DKW was reflected in a marked increase in the ratio of $\mathrm{DKW} / \mathrm{WKW}$.

Table $I$. Summary of experimental data for all animals

\begin{tabular}{|c|c|c|c|c|c|c|c|c|c|c|}
\hline \multirow{2}{*}{ Age, days } & \multirow{2}{*}{ Body wt, g } & \multicolumn{2}{|c|}{ Kidney $w t^{1}{ }^{g} \mathrm{~g}$} & \multicolumn{2}{|c|}{$\mathrm{C}_{\mathrm{IN}, 2}{ }^{2} \mathrm{ml} / \mathrm{min}$} & \multicolumn{2}{|c|}{$\begin{array}{l}\text { Plasma glucose, } \\
\mathrm{ml} / 100 \mathrm{ml}\end{array}$} & \multirow{2}{*}{$\mathrm{TmG}, \mathrm{mg} / \mathrm{min}$} & \multirow{2}{*}{$\begin{array}{c}\mathrm{TmG} / \mathrm{CrN}_{\mathrm{N}} \\
\mathrm{mg} / \mathrm{ml}\end{array}$} & \multirow{2}{*}{$\begin{array}{c}\left(\mathrm{C}_{\mathrm{NA}} \times 100\right) / \mathrm{C}_{\mathrm{IN}} \\
\text { at } \mathrm{TmG}, \%\end{array}$} \\
\hline & & Wet & Dry & Control & At $\operatorname{Tm} G$ & Threshold & $\operatorname{TmG}$ & & & \\
\hline 0.75 & 274 & 4.2 & 0.60 & 0.50 & 0.64 & 200 & 637 & 2.7 & 4.22 & 1.2 \\
\hline 1.50 & 250 & 5.4 & 0.95 & 0.60 & 0.71 & 199 & 776 & 3.0 & 4.29 & 24.0 \\
\hline 3.0 & 450 & 8.3 & 1.20 & 1.40 & 1.74 & 236 & 594 & 7.4 & 4.26 & 1.6 \\
\hline 4.0 & 430 & 7.9 & 0.90 & 1.90 & 2.0 & 190 & 511 & 7.1 & 3.55 & 3.1 \\
\hline 5.0 & 540 & 9.4 & 1.05 & 2.0 & 1.86 & 193 & 887 & 6.7 & 3.60 & 21.0 \\
\hline 7.0 & 550 & 10.6 & 1.20 & 2.1 & 2.0 & 224 & 800 & 7.2 & 3.60 & 3.3 \\
\hline 10 & 700 & 14.1 & 1.60 & 3.5 & 3.7 & 240 & 519 & 12.9 & 3.49 & 1.2 \\
\hline 10 & 450 & 13.1 & 1.80 & 3.2 & 2.9 & 220 & 719 & 9.7 & 3.35 & 3.9 \\
\hline 12 & 425 & 10.1 & 1.45 & 1.7 & 1.7 & 210 & 573 & 6.1 & 3.59 & 3.9 \\
\hline 14 & 900 & 15.0 & 1.90 & 4.0 & 3.5 & 237 & 387 & 11.8 & 3.37 & 1.4 \\
\hline 14 & 600 & 8.3 & 1.30 & 2.7 & 2.1 & 195 & 491 & 6.8 & 3.24 & 3.5 \\
\hline 18 & 660 & 14.05 & 1.90 & 3.7 & 5.0 & 217 & 465 & 19.2 & 3.74 & 0.5 \\
\hline 19 & 666 & 14.3 & 1.95 & 3.8 & 3.6 & 245 & 603 & 15.3 & 3.57 & 0.3 \\
\hline 21 & 1350 & 22.8 & 2.95 & 6.0 & 6.9 & 250 & 604 & 22.2 & 3.22 & 0.8 \\
\hline 22 & 1200 & 23.6 & 2.70 & 7.1 & 8.2 & 3 & 574 & 26.9 & 3.28 & 0.2 \\
\hline 23 & 1350 & 24.6 & 4.40 & 9.3 & 9.7 & 200 & 452 & 30.0 & 3.09 & 3.4 \\
\hline 34 & 1900 & 34.0 & 7.1 & 11.6 & 11.3 & 238 & 448 & 31.2 & 2.76 & 6.0 \\
\hline 35 & 2000 & 37.2 & 6.3 & 10.8 & 9.8 & 240 & 408 & 26.9 & 2.75 & 1.2 \\
\hline 39 & 1575 & 28.1 & 7.3 & 10.3 & 14.6 & 224 & 460 & 44.0 & 3.01 & 0.6 \\
\hline 40 & 1375 & 27.0 & 7.2 & 11.2 & 12.9 & 254 & 395 & 42.7 & 3.31 & 0.7 \\
\hline
\end{tabular}

1 Both kidneys.

${ }^{2} \mathrm{C}_{\mathrm{IN}}$ : clearance of inulin; TmG: maximal tubular transport of glucose.

${ }^{3}$ Threshold exceeded before definition. 

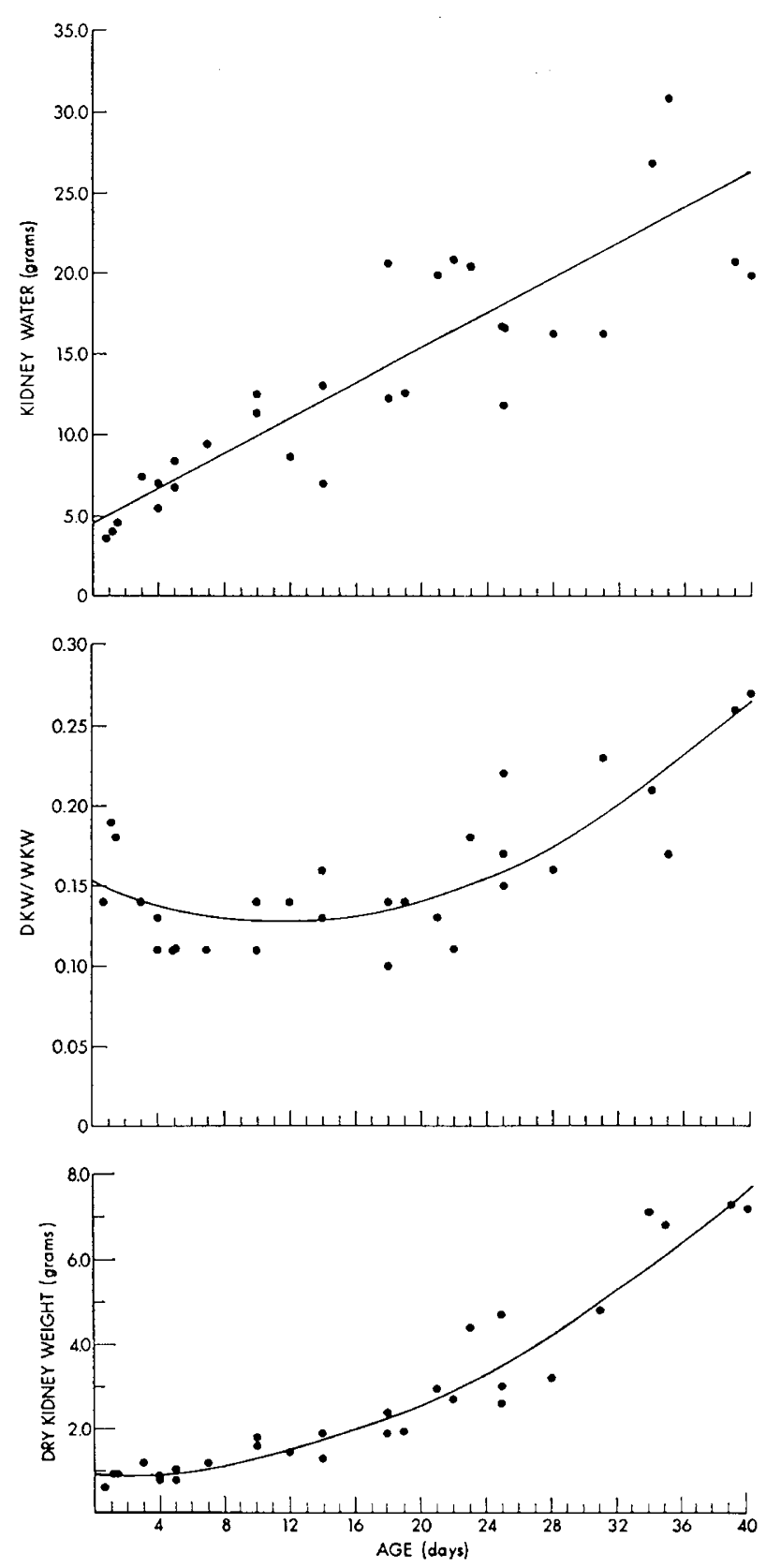

Fig. 1. Change in kidney weight and water content with age. Each point represents the combined value of both kidneys. In addition to the 20 animals represented in our glucose data there are 9 puppies which, because of physiologic instability, were eliminated prospectively but are included in this analysis only. Regression with age for kidney water was $\mathrm{y}=0.54 \mathrm{x}+4.46, \mathrm{x}=$ 0.88 ; for dry kidney wt/wet kidney wt ( $\mathrm{DKW} / \mathrm{WKW}$ ), $\mathrm{y}=0.000166$ $\mathrm{x}^{2}-0.00381 \mathrm{x}+0.15, \mathrm{r}=0.82$, deviation from linearity significant $(P=0.10)$; for DKW, y $=0.00424 \mathrm{x}^{2}+2.73 \mathrm{x}+0.89, \mathrm{r}=0.96$, deviation from linearity significant $(P<0.01)$.

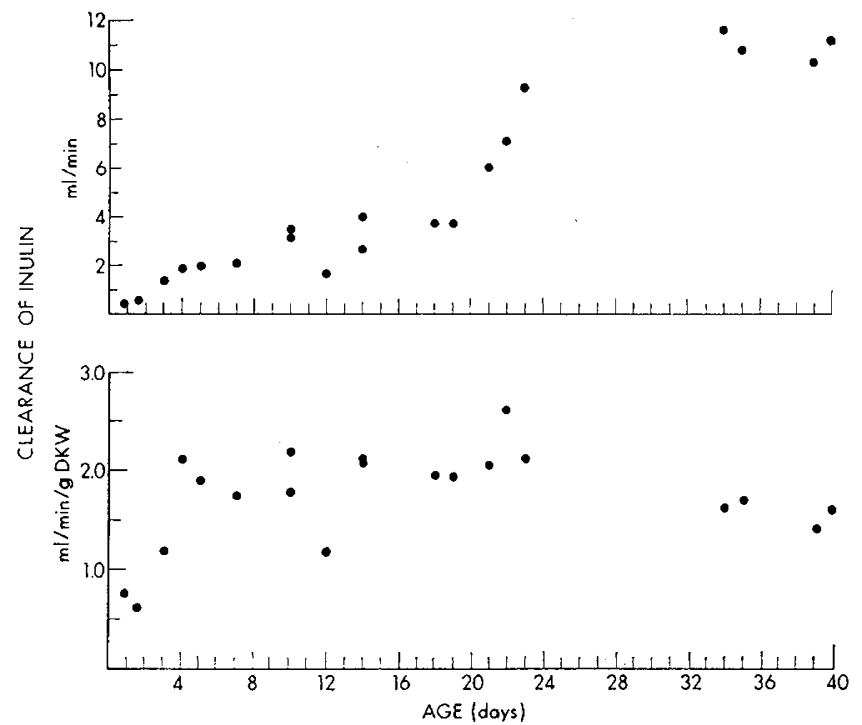

Fig. 2. Glomerular filtration rate as a function of age. Absolute rate of filtration is shown in the upper panel $\left(y=-0.00044 \mathrm{x}^{3}+\right.$ $\left.0.027 \mathrm{x}^{2}-0.14 \mathrm{x}+1.4, \mathrm{r}=0.97\right)$; filtration rate per gram of dry kidney in the lower. $D K W$ : dry kidney weight.

Examination of the $\mathrm{C}_{\mathrm{IN}}$ (Fig. 2) revealed a pattern of increase with age which appeared to be curvilinear with a slow rate of increase over the first 2 or 3 weeks relative to a somewhat more rapid rate thereafter. Indeed, the data best fit a third order regression equation, although the departure from linearity may have been accidental. Analysis of $\mathrm{C}_{\mathrm{YN}}$ per gram of $\mathrm{DKW}$ as a function of age showed wide scatter of the experimental points with no demonstrable correlation.

Although both an increase [6] and a decrease [13, 24] in glomerular filtration rate have been observed at high filtered loads of glucose, no consistent changes in the $\mathrm{C}_{\mathrm{IN}}$ were apparent in our data when initial values were compared with those values at high glucose loads, except for a consistent decrease in the $C_{X N}$ when the level of glucose in plasma exceeded $1,200 \mathrm{mg} / 100 \mathrm{ml}$.

Analysis of the glucose threshold as a function of age (Fig. 3) revealed a statistically significant positive regression $(0.05>P>0.01)$. However, the increase with age was small and all values fell within the $95 \%$ confidence limits for the glucose threshold of adult dogs examined in our laboratory as well as those reported in the literature $[24,37,38,40]$.

TmG as a function of age is shown in Fig. 4. A pattern similar to that observed for the relation of $\mathrm{DKW}$ and $\mathrm{C}_{\mathrm{XN}}$ to age is apparent, with an accelerated rate of increase beginning at the $3 \mathrm{rd}$ week of life. The data accordingly are best described by a nonlinear 


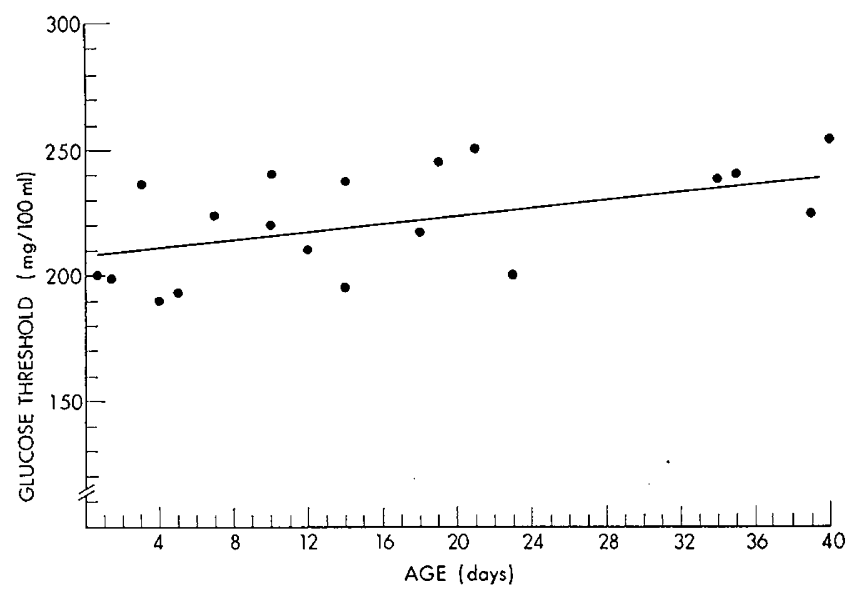

Fig. 3. Glucose threshold as a function of age. $y=0.90 \mathrm{x}+$ 206.97. $\mathrm{r}=0.46,0.05>P>0.01$.

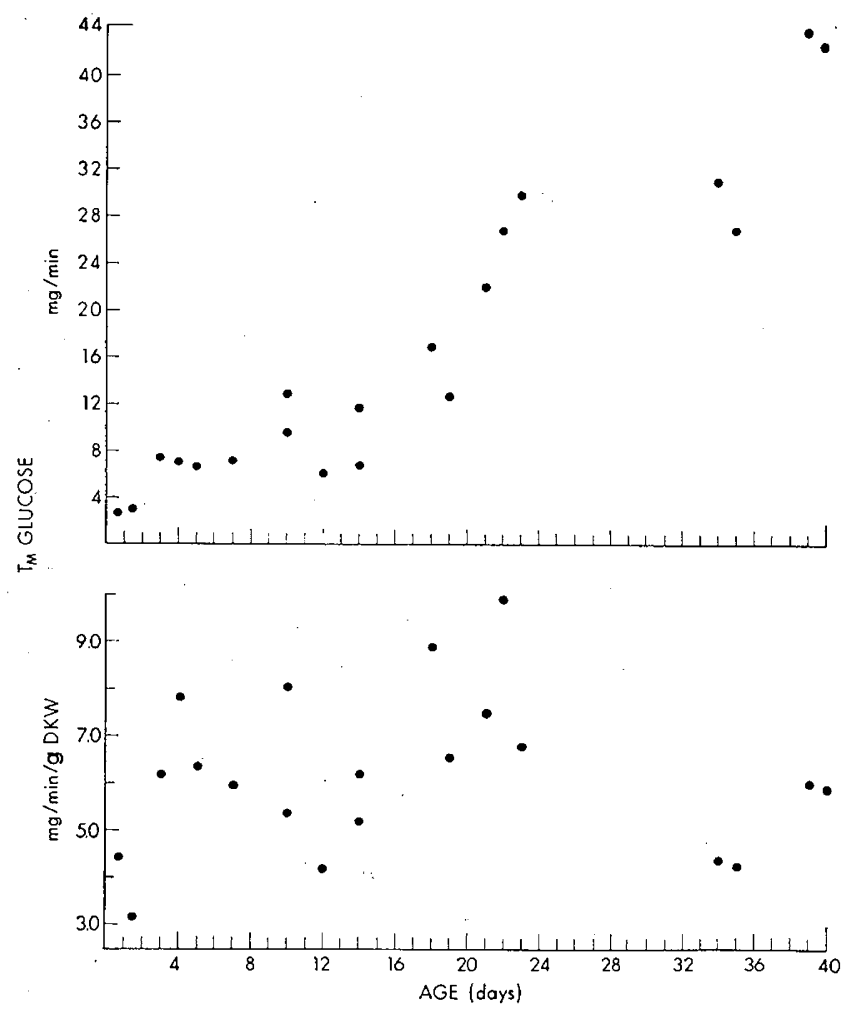

Fig. 4. Maximal tubular reabsorption $(\mathrm{Tm})$ of glucose as a function of age. Absolute rate shown in the upper panel $\left(y=0.007 \mathrm{x}^{2}\right.$ $+0.68 \mathrm{x}+2.6, \mathrm{r}=0.95)$; $\mathrm{Tm}$ of glucose per gram of dry kidney (DKW) shown in the lower panel.

regression, although, again, the departure from linearity may have been accidental. When the TmG, as an index of proximal tubular function, was factored by $\mathrm{DKW}$, as an index of proximal tubular growth, no clear pattern was apparent over the entire age range studied.

It has been noted previously that the apparent TmG decreases as fractional sodium excretion increases [24]. A similar relation between sodium and glucose reabsorption was present in the adult dogs and in the puppies 21-40 days of age. In the puppies 10-14 days of age, however, as fractional sodium excretion increased to levels in excess of $20 \%$ (beyond the periods used for calculation of $\mathrm{TmG}$ ), no decrease in glucose reabsorption was seen. In the animals from birth to 7 days of age, glucose reabsorption continued to rise with increasing filtered loads even though fractional sodium excretion reached levels as high as $25 \%$.

The ratio of $T m G$ to $C_{I N}$ is related to age in Fig. 5 . The ratio was high during the first 3 days of life, fell markedly by day 4 , and thereafter continued to decrease at a slower rate until levels were achieved that were similar to values found in adult animals. An exponential rate of decline in the ratio is described. The deviation of this curve from a linear regression is significant $(P<0.05)$, making it quite unlikely that undue emphasis has been placed upon the early ages with high values. It should be noted that if the true maximal rate of reabsorption was not achieved in the youngest animals, the ratio of $\operatorname{TmG}$ to $\mathrm{C}_{\mathrm{IN}}$ is even higher during the first few days than reflected by our data.

A comparison of splay in the oldest and youngest puppies is shown in Fig. 6. Note that while all points follow a similar pattern, comparison between the two age groups reveals that at each $\mathrm{L} / \mathrm{Tm}$ quantile values of $\mathrm{T} / \mathrm{Tm}$ for the younger puppies are less than those for the older puppies. In addition, the point at which

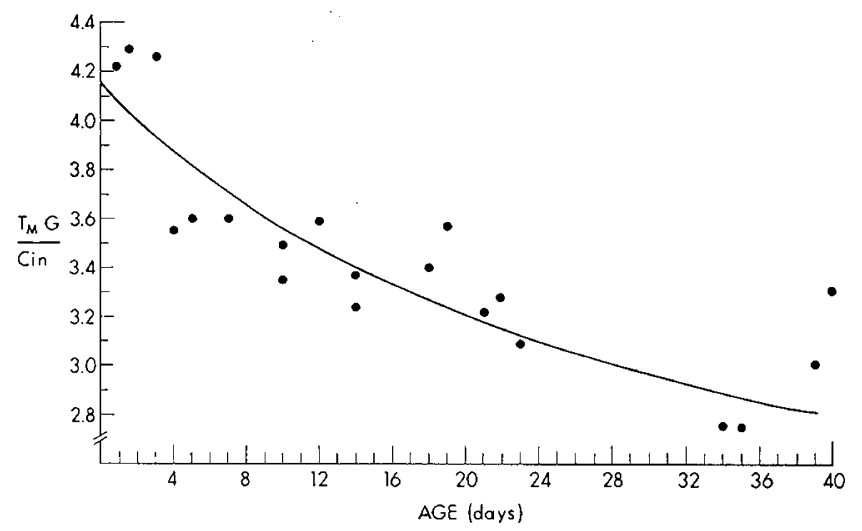

Fig. 5. Ratio of maximal tubular reabsorption of glucose $(T m G)$ to inulin clearance $\left(C_{i n}\right)$ as a function of age. $\mathrm{y}=1.64 \mathrm{e}^{-0.0419 \mathrm{x}}+$ $2.5, \mathrm{r}=0.87$. 
reabsorption becomes incomplete occurs at a lower filtered load in the younger animals.

\section{Discussion}

The maximal rate at which the proximal tubule is able to reabsorb glucose has been used as one of the classic markers of tubular function in adult animals, including man [40], and has served as a cornerstone of support for Smith's hypothesis [39] of functional glomerular preponderance in the immature kidney. Low ratios of TmPAH and $\mathrm{C}_{\mathrm{PAH}}$ to $\mathrm{C}_{\mathrm{IN}}[4,34,45,46,48]$, decreased fractional tubular reabsorption of certain amino acids [7] and of phosphate [12, 26, 31], and the high anatomical ratio of glomerular surface area to proximal tubular volume [17] added further support to this interpretation.

More recently, however, a number of studies have suggested that such a broad generalization of the behavior of the infant kidney may not describe adequately the glomerulotubular relation for all substances. The low ratios of $\mathrm{C}_{\mathrm{PAH}}$ to $\mathrm{C}_{\mathrm{IN}}$ have been shown to be secondary to decreased extraction of PAH by the infant kidney [9] due to a relatively greater blood flow to juxtamedullary nephrons and thus to vasa recta [21, 27, 28]. There is no difference between infants and children in the ratio of tubular amino acid reabsorption to glomerular filtration rate [7], and no limitation in reabsorptive ability at 30-50 times normal blood levels for at least one amino acid [8]. Functional glomerulotubular balance has been shown for sodium and water in the young puppy [20], rat [10], and guinea pig [43]. These data suggest that the documented anatomical glomerular preponderance in the infant kidney may not have a consistent functional correlate, but rather that balance between filtration and reabsorption is present at all stages of postnatal development.

In comparison of data in the present study to values obtained in adult animals, the ratio of $\mathrm{TmG}$ to $\mathrm{C}_{\mathrm{IN}}$ for the youngest puppies was high, not low as found in premature infants [45], which suggests not glomerular but tubular preponderance during the first few days of life. To explain this difference, it is suggested either that the TmG was not reached in the studies of Tudvad [44] and Tudvad and Vesterdal [45], or that saline loading produced depression of the $\operatorname{TmG}[3,22,24$, 32].

Brodehl et al. [6] found no difference in the ratios of TmG to $\mathrm{C}_{\mathrm{IN}}$ between infants 2.5-24 weeks of age and older children. However, their youngest infants had

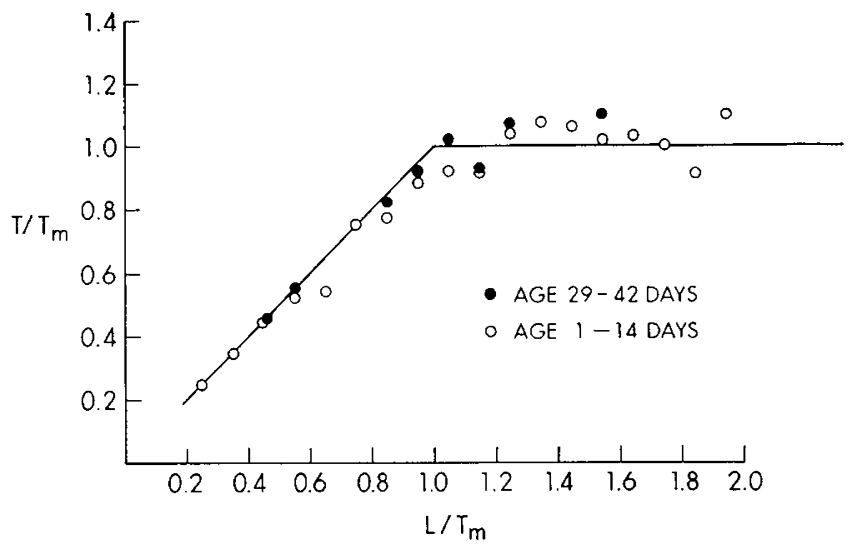

Fig. 6. Splay of glucose titration data. $T$ : glucose reabsorption; $L:$ filtered load of glucose. Both terms are factored by maximal tubular reabsorption $(T m)$ to permit pooling of data from individual animals. Each point represents a mean $\mathrm{T} / \mathrm{Tm}$ at $\mathrm{L} / \mathrm{Tm}$ quantiles of 0.1 .

high ratios of $T m G$ to $\mathrm{C}_{\mathrm{IN}}$, similar to the results in the youngest puppies in the present study (J. Brodehl, personal communication).

The presence of an apparently mature transport system for glucose relative to glomerular filtration does not, of course, necessarily imply a similar degree of tubular development for other substances. Smith [39] suggested that the tubular reabsorptive capacity for glucose in infants might be more highly developed than that for other substances. This has been shown to be true in the sheep fetus [1]. Since anaerobic glycolysis has been shown to proceed at a greater rate in newborn rats [49], rabbits [49], puppies [11], and premature infants [35], than in older animals and term infants, it is conceivable that the increased glucose utilization of this metabolic pathway might result in a generalized enhancement of glucose metabolism in neonates. Studies in rats [18] and infants [35] support this speculation.

Thus, although maximal glucose reabsorption, by virtue of its suggested unique level of maturation and its dependence on such variables as extracellular volume, glomerular filtration, and fractional sodium excretion, may not be representative of other proximal tubular mechanisms in the developing kidney, these data do suggest that glomerular preponderance is not present, even in very young animals.

The renal threshold for glucose has not been studied previously either in experimental animals or in infants. It is often stated, however, that small amounts of glycosuria are not infrequent in neonates [33], especially premature infants, in whom the degree of struc- 
tural maturation is more comparable to the younger puppies. It is surprising, therefore, that such small differences with age were found in the glucose thresholds of the puppies. The slightly positive regression of glucose threshold with age that we observed nonetheless is real. It should be recognized that the glucose titration technique reflects overall glomerulotubular balance and not that of single nephrons. An analysis of splay, however, allows inferences to be made as to the glomerulotubular balance of populations of nephrons. If the lower threshold in the younger puppies is due to greater nephron heterogeneity, this should be manifest by an increased splay in their titration curves relative to older puppies and adult dogs. A comparison of splay in the youngest and the oldest puppies (Fig. 6) indeed does demonstrate an increase in splay and thus in functional heterogeneity in the younger animals. A minimal degree of splay was found in the older puppies, similar to adult dogs, in contrast to the marked splay in adult man $[25,40]$. It has been noted previously that the extent of splay in the glucose titration curve in man is greater than that in the dog [39]; therefore, the infant, likewise, may show a much greater degree of splay than the puppy, the result of which would be a lower glucose threshold in infants.

The nonlinear increase in total kidney glomerular filtration rate observed in micropuncture studies in guinea pigs [43] supports the pattern of nonlinearity in our data and suggests that the slow rate of increase in the $\mathrm{C}_{\mathrm{IN}}$ which we observed over the first 2 or 3 weeks of life reflected, as in the guinea pig, primarily changes in the rate of filtration in juxtamedullary nephrons and that the rapid increase thereafter was caused by changes in the filtration rate of the outer cortical nephrons. Parallel studies in which the distribution of renal blood flow was studied by the ${ }^{133} \mathrm{Xe}$ washout method in littermates of the puppies used in the present investigation demonstrated a similar developmental pattern [2].

The maturation of tubular reabsorption may be caused by an increase in the number of functional units, by a maturation of cellular reabsorptive mechanisms, or by both. Micropuncture studies in the developing guinea pig kidney [43] suggest an increase in the number of units as the primary factor. Analysis of TmG per gram of DKW over the first 3 weeks revealed a significant increase $(P=0.025)$, which suggests changes transcending a simple increase in tubular mass or number of functional units. In vitro studies of PAH uptake in dog kidney slices $[19,23]$ support this conclusion.

\section{Summary}

The renal handling of glucose was studied in puppies from birth to 40 days of age in order to investigate glomerulotubular balance of the developing kidney and to determine whether the previously demonstrated morphologic heterogeneity and glomerular preponderance of the nephrons of the immature kidney have functional counterparts.

The glucose threshold increased slightly with age although all values fell within the range observed in adult dogs. The ratio of $\mathrm{TmG}$ to $\mathrm{C}_{\mathrm{IN}}$ was high at birth, decreased markedly by day 4 , and reached adult values after 3 weeks of age. This pattern of change reflected the more rapid increase in $\mathrm{C}_{\mathrm{IN}}$ than $\mathrm{TmG}$. These findings fail to support the concept of glomerular preponderance as a characteristic of the immature kidney.

The slightly lower threshold for glucose in the youngest puppies appeared to reflect increased nephron heterogeneity, as demonstrated by greater splay of the titration curve in the youngest animals. This finding may reflect a population of nephrons with relative glomerular preponderance, despite the presence of glomerulotubular balance for the kidney as a whole.

\section{References and Notes}

1. Alexander, D. P., and Nixon, D. A.: Reabsorption of glucose, fructose and mesoinositol by the fetal and postnatal sheep kidney. J. Physiol., 167: 480 (1963).

2. Aschinberg, L. C., Goldsmith, D., Olbing, H., Hardy, M., Sprtzer, A., Edelmann, C. M., Jr., and Blaufox, M. D.: Neonatal changes in renal blood flow distribution in puppies. Fifth International Congress of Nephrology, Mexico City, Mexico, p. 12 (1972).

3. BAINes, A. D.: Effect of extracellular fluid volume expansion on maximum glucose reabsorption rate and glomerular tubular balance in single rat nephrons. J. Clin. Invest., 50: 2414 (1971).

4. Barnetr, H. L.: Kidney function in young infants. Pediatrics, 5: $171(1950)$.

5. Bergmeyer, H., AND Bernt, E.: Determination with glucose oxidase and peroxidase. In: Methods of Enzymatic Analysis, p. 123 (Academic Press, New York, 1965).

6. BronfHL, J., Franken, A., And Gellissen, K.: Maximal tubular reabsorption of glucose in infants and children. Acta Paediat. Scand., 61: 413 (1972); Personal communication (1973).

7. Brodehl, J., AND Gellissen, K.: Endogenous renal transport of free amino acids in infancy and childhood. Pediatrics, 42: 395 (I968).

8. Brodehl, J., Gelisssen, K., And Hagge, W.: Die tubuläre Rückrecorption der freien Aminosäuren im Säuglings- und Kindesalter. Mschr. Kinderheilk., 116: 305 (1968).

9. Carcagno, P. L., and Rubin, M. I.: Renal excretion ci para- 
aminohippurate in infants and children. J. Clin. Invest., 42: 1632 (1963).

10. Câpek, K., Dlouha, H., Fernandez, J., and Popr, M.: Regulation of proximal tubular reabsorption in early postnatal period of infant rats: Micropuncture study. Proceedings of the International Union of Physiological Sciences, Vol. VII, XXIVth International Congress, Washington, D.C., 1968).

11. CÂPeK, K., AND Kleinzeller, A.: Ontogenetic changes in the transport of water and elcctrolytes by kidney slices. Symposium of the Czechoslovak Academy of Sciences, Prague, p. 55, 1960).

12. Dean, R. F. A., ANd MaCance, R. A.: Phosphate clcarances in infants and adults. J. Physiol., 107: 182 (1948).

13. Dempster, W. J., Eggleton, M. G., and Shuster, S.: The effect of hypertonic infusions on glomerular filtration rate and glucose reabsorption in the kidney of the dog. J. Physiol. (London), 132: 213 (1956).

14. Edelmann, C. M., JR.: Glomerulo-tubular balance in the developing kidney. Proceedings of the Fourth International Congress of Nephrology, Stockholm, 1969, Vol. 1, p. 22 (S. Karger, Basel, 1970).

I5. Edelmann, C. M., JR.: Maturation of the neonatal kidney. Proceedings of the Third International Congress of Nephrology, Washington, D.C., 1966, Vol. 3, p. 1 (S. Karger, Basel, 1967).

16. Edelmann, C. M., JR., and SpItzer, A.: The maturing kidney. J. Pediat., 75: 509 (1969).

17. Fetterman, G. H., Shuplock, N. A., Philipp, F. J., And GREGG, H. S.: The growth and maturation of human glomeruli and proximal convolutions from term to adulthood: Studies by microdissection. Pediatrics, 35: 601 (1965).

18. Fitzgerald, J. F., Reiser, S., and Christiansen, P. A.: Developmental pattern of sugar and amino acid transport in the postnatal rat small intestine. Pediat. Res., 5: 698 (1971).

19. Ноoк, J. B., Williamson, H. E., ANn Hirsch, G. H.: Functional maturation of renal PAH transport in the dog. Can. J. Physiol. Pharmacol., 48: 169 (1970).

20. Horster, M., And Valtin, H.: Postnatal development of renal function: Micropuncture and clearance studies in the dog. J. Clin. Invest., 50: 779 (1971)

21. Jose, P. A., Logan, A. G., Slotkoff, L. M., Lillienfield, L. S., Calcagno, P. L., and Eisner, G. M.: Intranrenal blood flow distribution in canine puppies. Pediat. Res., 5: 335 (1971).

22. Keyes, J. L., and Swanson, R. E.: Dependence of glucose Tm on GFR and tubular volume in the dog kidney. Amer. J. Physiol., 221: 1 (1971)

23. KIM, J. K., Hirscri, G. H., AND Hook, J. B.: In vitro analysis of organic ion transport in renal cortex of the newborn rat. Pediat. Res., 6: 600 (1972).

24. Kurtzman, N. A., Whime, M. G., Rogers, P. W., and Flynn, J. J., III: Relationship of sodium reabsorption and glomerular filtration rate to glucose reabsorption. J. Clin. Invest., 51: 127 (1972).

25. LetTeRI, J. M., AND Wf.sson, L. G., JR.: Glucose titration curves as an estimate of intrarenal distribution of glomerular filtrate in patients with congestive failure. J. Lab. Clin. Med., 65: 387 (1965).

26. McCrory, W. W., Forman, C. V., McNamara, H., and BarNETT, H. L.: Renal excretion of phosphate in newborn infants. J. Clin. Invest., 31: 357 (1952)

27. Moore, E. S., Satrasook, S. S., Fine, B. P., Katz, M. C., And Edfimann, C. M., Jr.: PAH extraction in puppies. Procecdings of the 39th Annual Mceting of th: Scciety for Pediatric Research, A.lantic City, N. J., p. 1 I4 (1969).

28. Olring, H., Blaufox, M. D., Aschinberg, L. C., Silikalns, G. I., Bernstein, J., Spitzer, A., and Edelmann, C. M., JR.: Postnatal changes in renal blood flow distribution in puppies. J. Clin. Invest., 52: 2885 (1973)

29. Osathanondh, V., and PotTer, E. L.: Development of human kidney as shown by microdissecion. IV. Development of tubular portions of nephrons. Arch. Pathol., S2: 391 (1966).

30. Potter, D., Jarrah, A., Sakai, T., Harrait, J., and Holliday, M. A.: Character of function and size in kidney during normal growth of rats. Pediat. Res., 3: 51 (1969).

31. Richmond, J. B., Kravitz, H., Segar, W., and Waisman, H. A.: Renal clearance of endogenous phosphate in infants and children. Proc. Soc. Exp. Biol. Medl., 77: 83 (1951).

32. Robson, A. M., Srivastava, P. L., and Bricker, N. S.: The influence of saline loading on renal glucose reabsorption in the rat. J. Clin. Invest., 47: 329 (1968).

33. Rubin, M. I.: Urine and urination. In: W. E. Nelson: Textbook of Pediatrics, Ed. 8, p. 1094 (W. B. Saunders, Philadelphia, 1964).

34. Rubin, M. I., Bruck, E., AND Rapoport, M.: Maturation of renal function in childhood. J. Clin. Invest., 28: 1144 (1949).

35. Sabata, V., Stubbe, P., and Wolf, H.: Energy metabolism in the premature fetus. Biol. Neonate, 19: 299 (1971).

36. Shankf., S. W., Robson, A. M., ANd Bricker, N. S.: On the mechanism of the splay in the glucose titration curve in advanced experimental renal disease in the rat. J. Clin. Invest., 46: 164 (1967)

37. Shannon, J. A., Fariber, S., and Troast, L.: The measurement of glucose Tm in the normal dog. Amer. J. Physiol., 133: 752 (1941).

38. Shannon, J. A., And Fismer, S.: The renal tubular reabsorption of glucose in the normal dog. Amer. J. Physiol., 122: 765 (1938).

39. Sмrтh, H. W.: The Kidney: Structure and function in health and disease, p. 492 (Oxford University Press, New York, 1951).

40. Smith, H. W., Golmring, W., Chasis, H., Ranges, H. A., and BRADI.FY, S. E.: The application of saturation methods to the studly of glomerular and tubular function in the human kidney. J. Mt. Sinai Hosp., 10: 59 (1943).

41. SNedecor, G. W.: Statistical Methods, Ed. 5 (The Iowa State University Press, Ames, Iowa, 1956).

42. Solomon, S., AND CÂPEK, K.: Regulation of superficial single nephron glomerular filtration rates in infant rats. Proc. Soc. Exp. Biol. Med., 139: 325 (1972).

43. Spitzer, A., AND Brandis, M.: Functional and morphologic maturation of the superficial nephrons. Relationship to total kidney function. J. Clin. Invest., 53: (1974).

44. Tulvad, F.: Sugar reabsorption in prematures and full-term babics. Scand. J. Clin. Lab. Invest., 1: 281 (1949).

45. Tudvad, F., ANd Vesterdal, J.: The maximal tubular transfer of glucose and para-aminohippurate in premature infants. Acta Paediat., 42: 337 (1953).

46. Vesterdal, J., and Tunvad, F.: Studics on the kidney function in premature and full-term infants by estimation of the inulin and para-aminohippurate clearances. Acta Paediat., 37: 429 (1950).

47. Walser, M., Davidson, D. G., and Ortoff, J.: The renal clearance of alkali-stable inulin. J. Clin. Invest., 3f: 1520 (1955). 
48. West, J. R., Smith, H. W., and Chasis, H.: Glomerular filtration rate, effective renal blood flow and maximal tubular excretory capacity in infancy. J. Pediat., 32: 10 (1948).

49. Whittam, R.: Sodium and potassium movements in kidney cortex slices from newborn animals. J. Physiol., 153: 358 (1960).

50. Promonta, Hamburg, West Germany.

51. Model 681, Harvard Apparatus Co., Inc., Millis, Mass.

52. Glucostat, Worthington Chemical, Freehold, N. J.

53. The London Co., Cleveland, Ohio.

54. The authors express grateful appreciation to Armida B. Martinez, Associate in Pediatrics, for expert technical assistance and supervision of laboratory analyses, and to Nicholas Gut- feld for computer analysis of data. Jean Massaro and Brunilda Furst provided excellent secretarial assistance.

55. This research was presented in part at the 42nd Annual Meeting of the Society for Pediatric Research, Washington, D.C., May 23-26, 1972, and was supported in part by United States Public Health Service Grants nos. 5 P0I AM 14877-13, 5 TI HL5267-14, 1FO3 AM 54096-01, The Sylvan League, Inc., and The Kidney Disease Institute of the State of New York.

56. Requests for reprints should be addressed to: M. A. NASH, M.D., Rose F. Kennedy Center, Rm. 721, 1410 Pelham Parkway S., Bronx, New York 10461 (USA).

57. Accepted for publication January 23, 1974. 